\title{
Precision Thermal Treatments, Atom Probe Characterization, and Modeling to Describe the Fe-Cr Metastable Miscibility Gap
}

\author{
ALEXANDER DAHLSTRÖM, FREDERIC DANOIX, PETER HEDSTRÖM, \\ JOAKIM ODQVIST, MALIN SELLEBY, and HELENA ZAPOLSKY
}

The Fe-Cr metastable miscibility gap has been studied by high-precision thermal treatments, Vickers micro-hardness (HV) measurements, and atom probe tomography (APT). Thermodynamic modeling further supplements the experimental work. The results obtained show that recent thermodynamic descriptions of the metastable miscibility gap found in literature generally overestimates the consolute temperature. We can show that the source of ambiguity in previous studies is most likely a lack of clear distinction between $\mathrm{Cr}-\mathrm{Cr}$ clustering and $\alpha^{\prime}$ formation. This distinction is here made by APT results, and it leads to a determined consolute temperature of $580 \pm 1{ }^{\circ} \mathrm{C}$ for $\mathrm{Fe}_{0.50} \mathrm{Cr}_{0.50}$. The revised thermodynamic modeling of the metastable miscibility gap captures the experimental results and is consistent with the overall picture from the $\mathrm{Fe}-\mathrm{Cr}$ data in the literature.

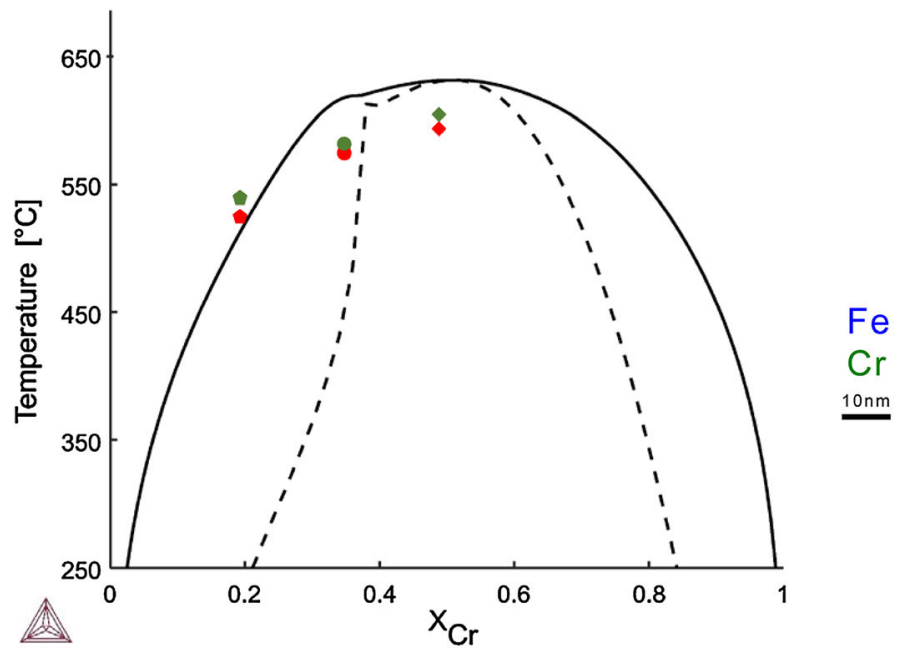

https://doi.org/10.1007/s11661-021-06145-4

(C) The Author(s) 2021
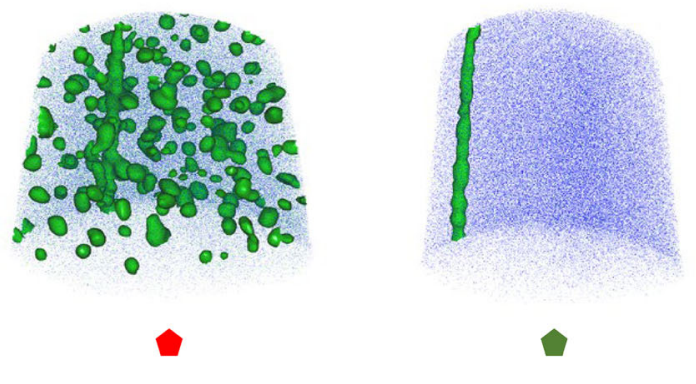

\section{INTRODUCTION}

TeCHNICAL development of Fe-Cr-based alloys

ALEXANDER DAHLSTRÖM is with the Normandie Université, Université de Rouen, INSA Rouen, CNRS, Groupe de Physique des Matériaux, 76000 Rouen, France and also with the Department of Materials Science and Engineering, KTH Royal Institute of Technology, 10044 Stockholm, Sweden. Contact e-mail: adahlstr@kth.se FREDERIC DANOIX and HELENA ZAPOLSKY are with the Normandie Université, Université de Rouen. PETER HEDSTRÖM, JOAKIM ODQVIST, and MALIN SELLEBY are with the Department of Materials Science and Engineering, KTH Royal Institute of Technology.

Manuscript submitted August 7, 2020; accepted December 23, 2020.

Article published online February 23, 2021 such as stainless steel is driven by their application in industry and consumer items. ${ }^{[1,2]}$ The widespread use of $\mathrm{Fe}-\mathrm{Cr}$ alloys is due to favorable mechanical properties, design. ${ }^{[2]}$ Their microstructure and thus innate mechanical properties can be broadly divided into four classes: austenitic, ferritic, martensitic, and austenitic-ferritic (duplex). In particular, ferritic $\mathrm{Fe}-\mathrm{Cr}$ alloys are of high interest in the nuclear industry where they are corrosion resistance, and flexibility of materials 
considered as structural materials for the next generation reactors. ${ }^{[3-7]}$ Their resistance to irradiation-induced swelling and thermal shock is especially attractive in this application. However, $\mathrm{Fe}-\mathrm{Cr}$ alloys with ferrite or martensite as the main phase, even austenitic stainless steel welds that contain high-temperature $\delta$-ferrite, are all susceptible to the " $475{ }^{\circ} \mathrm{C}$ embrittlement." This phenomenon is of critical concern for highly corrosion-resistant ferritic stainless steels at intermediate temperature, which are otherwise known to have good thermal stability. ${ }^{[8,9]}$ The " $475{ }^{\circ} \mathrm{C}$ embrittlement" is caused by the formation of a modulated nanostructure comprised of Fe-rich $\alpha$-ferrite and $\mathrm{Cr}$-rich $\alpha^{\prime}$-ferrite, which leads to a dramatic loss of toughness. The demixing of $\mathrm{Fe}$ and $\mathrm{Cr}$ is due to the miscibility gap that is present in the $\mathrm{Fe}-\mathrm{Cr}$ phase diagram. ${ }^{[10,11]}$ The $\alpha$ to $\alpha^{\prime}$ phase separation mechanisms that govern this demixing phenomenon is either spinodal decomposition or nucleation and growth. ${ }^{[12]}$ In addition to the technical relevance, binary $\mathrm{Fe}-\mathrm{Cr}$ alloys are favorable for fundamental studies of phase separation kinetics because of the wide miscibility gap, relatively slow decomposition process, and small $\alpha$ to $\alpha^{\prime}$ lattice mismatch.

There is a vast amount of literature available on $\mathrm{Fe}-\mathrm{Cr}$, including an extensive review by Xiong et al., ${ }^{[13]}$ that led to the most recent thermodynamic description of the binary $\mathrm{Fe}-\mathrm{Cr}$ system. ${ }^{[14]}$ In their work, ${ }^{[14]}$ the thermodynamic modeling was supported by atom probe tomography (APT) experiments focused on locating the spinodal line within the miscibility gap on the Fe-rich side to supplement prior experiments. ${ }^{[15]}$ However, recent works ${ }^{[16,17]}$ have indicated that the miscibility gap and in particular the consolute temperature is not conclusively established. In the present work, we, therefore, investigate the upper limit of the miscibility

Table I. Chemical Composition of the As-Delivered Alloys [At. Pct]

\begin{tabular}{lccccc}
\hline Alloy & $\mathrm{Cr}$ & $\mathrm{Ni}$ & $\mathrm{Al}$ & $\mathrm{C}$ & $\mathrm{Fe}$ \\
\hline $\mathrm{Fe}_{0.80} \mathrm{Cr}_{0.20}$ & 19.53 & 0.0093 & 0.0456 & 0.0011 & bal. \\
$\mathrm{Fe}_{0.65} \mathrm{Cr}_{0.35}$ & 34.61 & 0.0077 & 0.0407 & 0.0016 & bal. \\
$\mathrm{Fe}_{0.50} \mathrm{Cr}_{0.50}$ & 49.63 & - & 0.0428 & 0.0033 & bal. \\
\hline
\end{tabular}

Composition Analysis Performed by a Combination of Inductive-Coupled Plasma Optical Emission Spectroscopy (ICP-OES), Combustion, and X-ray Fluorescence (XRF).

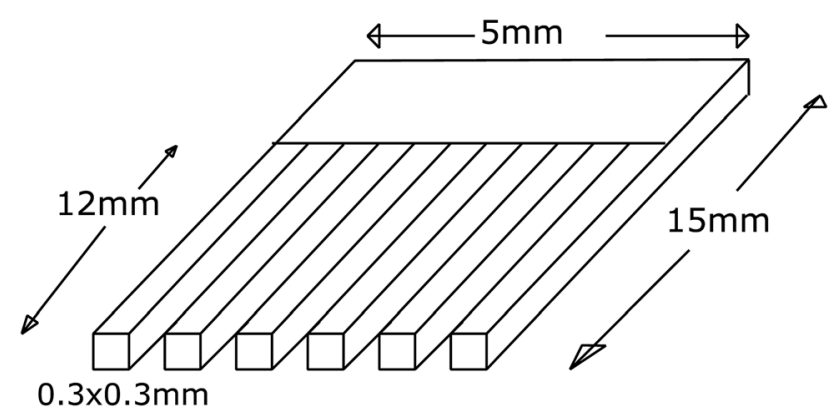

Fig. 1-Illustration of APT blanks. gap by distinguishing between phase separation and $\mathrm{Cr}-\mathrm{Cr}$ clustering. This is critical to be able to accurately determine the undercooling, which drives the temporal evolution of phase separation. The upper limit of the miscibility gap is located by APT results and Vickers micro-hardness (HV) measurements on samples exposed to high-precision thermal treatments. Thermodynamic modeling of the metastable miscibility gap is performed using the new experimental data and literature data.

\section{METHODS}

\section{A. Materials and Heat Treatments}

The investigated samples were fully ferritic $\mathrm{Fe}-\mathrm{Cr}$ model alloys, supplied by OCAS NV. Three $33 \mathrm{~kg}$ ingots were cast in a vacuum induction furnace, a $125 \times 125 \times$ $70 \mathrm{~mm}^{3}$ block was cut, reheated to $1200{ }^{\circ} \mathrm{C}$, and then hot-rolled to $15 \mathrm{~mm}$ thickness. The realized chemical composition upon delivery is provided in Table I. Before thermal aging, a $10 \times 15 \times 50 \mathrm{~mm}^{3}$ bar was cut and homogenized in air at $1100{ }^{\circ} \mathrm{C}$ for 2 hours followed by water quenching to room temperature. Thermal aging was performed in a Jofra 601 dry-block calibrator furnace, the temperature accuracy of the furnace during heat treatment was $\pm 0.9{ }^{\circ} \mathrm{C}$ verified by a K-type thermocouple. Two types of samples were prepared, $0.3 \mathrm{~mm}$ sheets that were later cut into comb-shaped samples for atom probe analysis (illustrated in Figure 1) and square samples for hardness measurements $\left(15 \times 10 \times 3 \mathrm{~mm}^{3}\right)$. After isothermal aging, the samples were quenched in water to room temperature.

The experimental matrix used in this study is provided in Table II. Literature data and the current thermodynamic description were used to select the starting point of heat treatments within the miscibility gap. When the limit was located within a temperature range, the interval was systematically reduced to determine the location of the miscibility gap boundary. Micro-hardness measurements were first used to study the presence of phase separation, ${ }^{[18]}$ then APT was used to verify the demixing.

\section{B. Hardness Measurements}

Vickers micro-hardness (HV) was tested on samples after polishing with a final 4000 grit SiC paper. Twelve measurements were made on each sample with a load of $200 \mathrm{~g} \quad\left(\mathrm{Fe}_{0.80} \mathrm{Cr}_{0.20}, \mathrm{Fe}_{0.65} \mathrm{Cr}_{0.35}\right)-300 \mathrm{~g} \quad\left(\mathrm{Fe}_{0.50} \mathrm{Cr}_{0.50}\right)$ and a dwell time of 10 seconds. The different loads were used to maintain similar indent sizes to assure equivalent measurement accuracy for all alloys. The reported $\mathrm{HV}$ value is the average after removing the lowest and highest two values. The standard deviation was calculated and presented as error bars. The measurements were performed in accordance with the ISO 6507-1 standard. The $\Delta \mathrm{HV}$ measurement is the measured relative change of hardness in as-quenched (AQ) state and after isothermal aging (i.e., $\Delta \mathrm{HV}=$ $\left.H V_{\text {aged }}-\mathrm{HV}_{\mathrm{AQ}}\right)$. 
Table II. The Experimental Matrix Used to Determine the Location of the Miscibility Gap, Heat Treatments and Experimental Technique, Lower Alloyed Steel Makes for Easier Determination

\begin{tabular}{|c|c|c|c|c|}
\hline Alloy & Temperature $\left({ }^{\circ} \mathrm{C}\right)$ & Time (h) & $\mathrm{HV}$ & APT \\
\hline $\mathrm{Fe}_{0.80} \mathrm{Cr}_{0.20}$ & 520 & 120 & $\checkmark$ & - \\
\hline $\mathrm{Fe}_{0.80} \mathrm{Cr}_{0.20}$ & 535 & 120 & $\checkmark$ & - \\
\hline $\mathrm{Fe}_{0.80} \mathrm{Cr}_{0.20}$ & 537 & 120 & $\checkmark$ & $\checkmark$ \\
\hline $\mathrm{Fe}_{0.80} \mathrm{Cr}_{0.20}$ & 539 & 120 & $\checkmark$ & 1 \\
\hline $\mathrm{Fe}_{0.80} \mathrm{Cr}_{0.20}$ & 540 & 120 & $\checkmark$ & $\boldsymbol{V}$ \\
\hline $\mathrm{Fe}_{0.65} \mathrm{Cr}_{0.35}$ & 550 & 120 & 2 & $\overline{-}$ \\
\hline $\mathrm{Fe}_{0.65} \mathrm{Cr}_{0.35}$ & 560 & 120 & 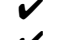 & 2 \\
\hline $\mathrm{Fe}_{0.65} \mathrm{Cr}_{0.35}$ & 563 & 120 & 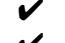 & 2 \\
\hline $\mathrm{Fe}_{0.65} \mathrm{Cr}_{0.35}$ & 565 & 120 & 2 & 2 \\
\hline $\mathrm{Fe}_{0.65} \mathrm{Cr}_{0.35}$ & 568 & 120 & $\checkmark$ & $\checkmark$ \\
\hline $\mathrm{Fe}_{0.65} \mathrm{Cr}_{0.35}$ & 570 & 120 & $\checkmark$ & $\checkmark$ \\
\hline $\mathrm{Fe}_{0.50} \mathrm{Cr}_{0.50}$ & 550 & 120 & $\checkmark$ & - \\
\hline $\mathrm{Fe}_{0.50} \mathrm{Cr}_{0.50}$ & 560 & 120 & 2 & $\bar{y}$ \\
\hline $\mathrm{Fe}_{0.50} \mathrm{Cr}_{0.50}$ & 565 & 120 & 2 & 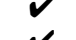 \\
\hline $\mathrm{Fe}_{0.50} \mathrm{Cr}_{0.50}$ & 570 & 120 & 2 & 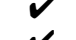 \\
\hline $\mathrm{Fe}_{0.50} \mathrm{Cr}_{0.50}$ & 575 & 120 & 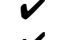 & $\checkmark$ \\
\hline $\mathrm{Fe}_{0.50} \mathrm{Cr}_{0.50}$ & 578 & 24,120 & 2 & $\checkmark$ \\
\hline $\mathrm{Fe}_{0.50} \mathrm{Cr}_{0.50}$ & 580 & 24,120 & $\checkmark$ & $\checkmark$ \\
\hline $\mathrm{Fe}_{0.50} \mathrm{Cr}_{0.50}$ & 595 & 145 & $\checkmark$ & $\checkmark$ \\
\hline
\end{tabular}

\section{Atom Probe Tomography (APT)}

\section{Instrument and reconstruction parameters}

The APT measurements were conducted using a CAMECA ${ }^{\circledR}$ LEAP 4000HR instrument. The final preparation of the blanks with dimensions $0.3 \times 0.3 \times$ $12 \mathrm{~mm}^{3}$ (Figure 1) was made using the classic two-step electropolishing method. ${ }^{[19]}$ For this purpose, a microloop was used with acidic/perchloric acid in 75/25-vol pct as the first step and in the second step, a 98/2-vol pct 2-butoxy-ethanol/perchloric acid solution was used. The analysis conditions for the LEAP instrument were as follows: operating temperature $50 \mathrm{~K}$, pulse fraction 20 pct, and detection rate 0.20 pct. Reconstructions were performed in IVAS 3.8, utilizing spatial distribution maps for depth calibration. ${ }^{[20,21]}$ Shank angle, image compression,, and evaporation field were adjusted in accordance with Vurpillot et al. ${ }^{[22]}$ In addition, the material-dependent evaporation field of the $\mathrm{Fe}-\mathrm{Cr}$ alloys was corrected in IVAS linearly depending on nominal composition and temperature, ${ }^{[23]}$ to account for the atomic volume under the assumption that Vegard's law holds.

\section{Statistical quantification of Cr segregation}

The reconstructed volumes were analyzed using frequency distribution in representative subvolumes for direct quantitative comparison of samples. ${ }^{[21]}$ The at. petCr frequency distribution diagrams were in this work generally taken from $25 \times 25 \times 75 \mathrm{~nm}^{3}$ blocks with a fixed bin volume of 50 ions. To quantify the composition amplitude in relation to a theoretically random distribution, the variation parameter $(V)$, as defined by Blavette et al., ${ }^{[24]}$ was used,

$$
V=\sum_{n=0}^{N}\left|P^{*}(n)-B(n)\right|
$$

where $P^{*}(n)$ is the observed experimental frequency distribution and $B(n)$ is the theoretical binomial frequency distribution. Thus, $V$ in this work is the normalized area difference, which generates a quantitative value $0 \leq V \leq 2$. If $V=0$ then $P^{*}(n)=B(n)$, and if $V=2$, there is no overlap of the $P^{*}(n)$ and $B(n)$ frequency distributions.

\section{The analysis of short-range order}

The radial distribution function (RDF) using APT data has previously been defined by Marquis ${ }^{[25]}$ and the bulk-normalized RDF can be defined as follows: ${ }^{[26]}$

$$
\operatorname{RDF}(r)=\frac{1}{\bar{\rho}} \frac{n_{\mathrm{RDF}}(r)}{(4 / 3) \pi\left((r+\Delta r / 2)^{3}-(r-\Delta r / 2)^{3}\right)}
$$

where $\mathrm{n}_{\mathrm{RDF}}(\mathrm{r})$ is the number of atoms in the shell at distance $r$ around each atom, $\bar{\rho}$ is the average ionic density of the volume: $(4 / 3) \pi\left((r+\Delta r / 2)^{3}-(r-\right.$ $\left.\Delta r / 2)^{3}\right)$ is the volume of each shell, and the distance $\Delta r$ is the thickness of each shell, in this work $\Delta r=0.25 \mathrm{~nm}$.

The Warren-Cowley $\left(\alpha_{\mathrm{WC}}\right)$ parameter is a way of describing the chemical dependency of $\mathrm{Cr}-\mathrm{Cr}$ shortrange ordering. ${ }^{[27,28]}$ The $\alpha_{\mathrm{WC}}$ parameters of APT data have been defined by Ceguerra et al. ${ }^{[29]}$ according to,

$$
\alpha_{\mathrm{WC}}=\frac{p(B \mid B)-x_{B}}{1-x_{B}}
$$

where $p(B \mid B)$ is the probability of finding $B$ - $B$ neighboring atoms and $x_{B}$ is the nominal mole fraction of element $B$. The probability of $p(B \mid B)$ is obtained from the first RDF peak as by Moody et al ${ }^{[30]}$ In this work, the first peak $\operatorname{RDF}(0)$ is obtained as in Zhou et al. ${ }^{[31]}$ The coordination number of the BCC structure is 8 so the probability of element $i$ and its reference state $j$ becomes,

$$
p_{i}(B \mid B)=\frac{\mathrm{RDF}(0)}{8 \zeta}, \quad p_{j}(B \mid B)=\frac{C_{0}}{8 \zeta}
$$

where $\zeta$ is the experimental detection efficiency and $C_{0}$ is the nominal concentration, a relative short-range order parameter has previously been used by Ceguerra et al.$^{[32]}$ Thus, the relative $\Delta$ SRO parameter is in this work is defined as,

$$
\Delta \mathrm{SRO}=\frac{\alpha_{\mathrm{WC}}^{i}-\alpha_{\mathrm{WC}}^{j}}{\alpha_{\mathrm{WC}}^{j}}
$$

where $\alpha_{\mathrm{WC}}^{j}$ is the WC parameter of the nominal composition and $\alpha_{\mathrm{WC}}^{i}$ corresponds to the WC parameter within the first RDF shell. Thus, if $\triangle \mathrm{SRO}=0$ there will be no short-range order present, if $\Delta \mathrm{SRO}<0$ there is negative co-segregation and if $\Delta \mathrm{SRO}>0$ there is positive co-segregation.

Similarly, short-range order has been investigated by APT using the nearest neighbor (NN) distributions by Mukherjee et al. ${ }^{[33]}$ In Table III, the classic variation 
parameter is given by $V$ as defined by Eq. [1], but the same quantification method has also been used to quantify the variations of the 1 st - and 5th-order $N N$ distributions, to analyze short-range interaction, ${ }^{[34,35]}$ with their respective abbreviation, which are $V$ (1st$\mathrm{NN})$ and $V(5$ th- $\mathrm{NN})$.

\section{Analysis of wavelength}

Concentration profiles were extracted from a $120-\mathrm{nm}$ long cylinder with $5 \mathrm{~nm}$ radius to maximize the signal-to-noise ratio, with a fixed bin size of $0.6 \mathrm{~nm}$ in the analysis direction. The autocorrelation function was used to extract the mean characteristic wavelength $\lambda_{\mathrm{m}}$ of the modulated structure by,

$$
R_{k}=\frac{\sum_{i=1}^{N-k}\left(C_{i}-\bar{C}\right)\left(C_{i+k}-\bar{C}\right)}{\sum_{i=1}^{N}\left(C_{i}-\bar{C}\right)^{2}}
$$

where $R_{k}$ is the correlation factor, $\bar{C}_{i}$ is the nominal concentration of element $i$ and $C_{i}$ is the local concentration of element $i$ in a specific binning volume. The selection of bin size is essential as it affects the local composition uncertainty as defined by Danoix et al. ${ }^{[36]}$ Uncertainty becomes significant in small volumes, while over-averaging might hide important features.

\section{Visualization of $\alpha^{\prime}$ morphology}

A simple assumption is that the nominal composition $\left(\mathrm{Cr}_{0}\right)$ is comprised of randomly distributed atoms in the volume. Then during phase separation, $\mathrm{Cr}$ atoms migrate out from the bulk to create $\mathrm{Cr}$-enriched $\alpha^{\prime}$, which results in $\mathrm{Cr}$ depletion of the matrix, given the assumption conservation of mass. Therefore, proxigrams over the $\mathrm{Cr}_{0}$ iso-concentration surface were used to estimate the at. pctCr in $\alpha^{\prime},{ }^{[37]}$ which is more easily done for clearly defined precipitates as in the $\mathrm{Fe}_{0.80} \mathrm{Cr}_{0.20}$ alloy.

The selection of $\alpha^{\prime}$ composition when the amplitude of $\mathrm{Cr}$ fluctuations is low or not fully developed means greater uncertainty. Hence, to visualize spinodal decomposition, we utilize the proxigram to plot the $\mathrm{Cr}$ sample count over the $\mathrm{Cr}_{0}$ surface and selected the $\alpha^{\prime}$ threshold as the $3 / 4$ maximum height of the distribution curve. As an example in the $\mathrm{Fe}_{0.50} \mathrm{Cr}_{0.50}$ alloy at $570{ }^{\circ} \mathrm{C}$ after 120 hours, we obtain a $3 / 4$ maximum at a position $x=$ $1.113 \mathrm{~nm}$ relative to the $\mathrm{Cr}_{0}$ iso-concentration surface at $x=0.0$ seen in Figure 2(a), this position is then equivalent to 58.72 at. pctCr in Figure 2(b) which is how we obtain the iso-concentration threshold used for $\alpha^{\prime}$ visualization.

\section{Thermodynamic Modeling}

CALculation of PHAse Diagrams (CALPHAD) is a thermodynamic modeling approach with widespread use in materials science, ${ }^{[38]}$ and it is an invaluable tool in materials design. ${ }^{[39]}$ Based on the minimization of Gibbs energy of the system, it is possible to predict its equilibrium state. In the present work, the body-centered cubic (BCC) $\alpha$ phase is described using a substitutional model assuming random mixing between $\mathrm{Fe}$ and $\mathrm{Cr}$. The molar Gibbs energy is given by,

$$
\begin{aligned}
G_{m}= & x_{\mathrm{Fe}}^{o} G_{\mathrm{Fe}}+x_{\mathrm{Cr}}^{o} G_{\mathrm{Cr}} \\
& +\mathrm{RT}\left(x_{\mathrm{Fe}} \ln \left(x_{\mathrm{Fe}}\right)+x_{\mathrm{Cr}} \ln \left(x_{\mathrm{Cr}}\right)\right)+{ }^{E} G_{m}
\end{aligned}
$$

where ${ }^{o} G_{i}$ is the Gibbs energy of a given constituent and ${ }^{E} G_{m}$ is the excess contribution to Gibbs energy. The excess Gibbs energy is expressed using a Redlich-Kister polynomial,

$$
{ }^{E} G_{m}=x_{\mathrm{Cr}} x_{\mathrm{Fe}} \sum_{k=0}^{n}{ }^{k} L\left(x_{\mathrm{Cr}}-x_{\mathrm{Fe}}\right)^{k}
$$

where the interaction parameters, ${ }^{k} L$, can be expressed as $L_{\mathrm{CrFe}}=a+b T$. In the present work, a sub-sub regular solution description was used. A drawback of the model is that it does not explicitly take short-range ordering (SRO) into account. Instead, SRO can be taken into account through the excess energy term, ${ }^{[38]}$ and the interaction parameters were here re-optimized to highlight the effect of SRO.

\section{RESULTS AND DISCUSSION}

\section{A. The $\mathrm{Fe}_{0.65} \mathrm{Cr}_{0.35}$ Reference State Investigation}

Solution-treated $\mathrm{Fe}_{0.65} \mathrm{Cr}_{0.35}$ samples were investigated to ensure a homogenous $\mathrm{Cr}$ distribution in the as-quenched reference state. Energy-dispersive spectroscopy (EDS) in an electron microscope (Zeiss XB 540) was used first. The EDS analysis consisted of three $1 \mathrm{~mm}$ homogeneous line scans on the surface of a HV-prepared sample. Thus, three line scans in the thickness directions were also made which consistently gave a 0.2 at. pct $\mathrm{Cr}$ deficit at the surface, and the $\mathrm{Cr}$ depleted zone was $\sim 60 \mu \mathrm{m}$ deep. Hence, 6 quantitative spot analyses were made in the center in the thickness direction stepping $5 \mu \mathrm{m}$ in the thickness direction, and the spot analyses were consistent with a standard deviation of 0.2 at. pctCr.

Subsequently, the solution-treated $\mathrm{Fe}_{0.65} \mathrm{Cr}_{0.35}$ alloy was investigated by APT, a resulting $20 \times 20 \times 60 \mathrm{~nm}^{3}$ volume of $\mathrm{Fe}$ and $\mathrm{Cr}$ ions is showed in Figure 3(a). To assess the $\mathrm{Cr}$ homogeneity $V$ analysis is used as a measurement. In Figure 3(b), the $\mathrm{Cr}$ frequency distributions are presented by the experimentally observed (Cr-Obs.) and the binomial (Cr-Bin.) distributions, and their difference is given as experimental minus random (EMR). The EMR curve reveals that there are random fluctuations of $\mathrm{Cr}$ within the solution-treated sample. The result shows that $V$ is highly sensitive to any fluctuations that deviate from the theoretical randomness. In this case, the as-quenched solution-treated state gives $V=0.026$, in agreement with previous reports. ${ }^{[18,40]}$

Statistical analysis of the APT results is essential to determine whether the elemental distributions are homogeneous or not. Furthermore, minor $\mathrm{Cr}$ segregation can easily be detected in the solution-treated state by the $\mathrm{Cr}$ concentration frequency distributions. In this case, both EDS and APT revealed a satisfactory level of homogeneity in the as-quenched reference state. Thus, the solution treatment 2 hours at $1100^{\circ} \mathrm{C}$ was applied to all alloys, followed by APT homogeneity verification. 
Table III. Statistical APT Analysis of $\mathrm{Fe}_{0.80} \mathrm{Cr}_{0.20}$ After 120 h Aging

\begin{tabular}{lcccccccc}
\hline Alloy & Temp. $\left({ }^{\circ} \mathrm{C}\right)$ & $V$ & $\Delta \mathrm{SRO}$ & $V(1 \mathrm{st}-\mathrm{NN})$ & $V(5 \mathrm{th}-\mathrm{NN})$ & $\Delta \mathrm{NN}(\mathrm{V})$ & $\alpha^{\prime}[\mathrm{at} . \mathrm{pctCr}]$ & $\bar{r}_{G}^{\alpha^{\prime}}(\mathrm{nm})$ \\
\hline $\mathrm{Fe}_{0.80} \mathrm{Cr}_{0.20}$ & 540 & 0.072 & 0.036 & 0.046 & 0.076 & 0.030 & - & - \\
$\mathrm{Fe}_{0.80} \mathrm{Cr}_{0.20}$ & 537 & 0.398 & 0.448 & 0.152 & 0.358 & 0.206 & 62.67 & $1.25 \pm 0.26$ \\
\hline
\end{tabular}

The analyzed volume was $40 \mathrm{~nm}^{3}$.

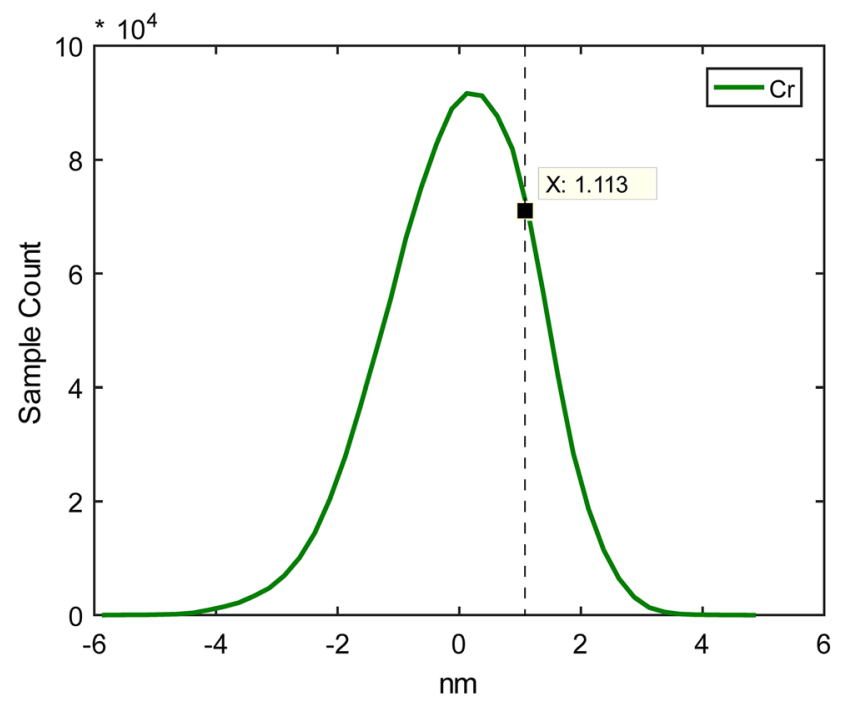

(a)

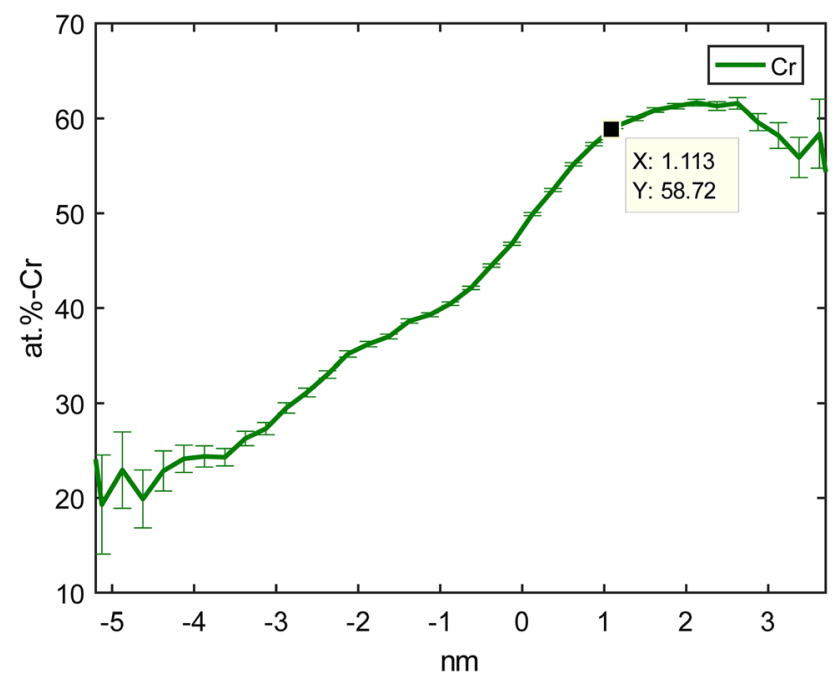

(b)

Fig. 2 - (a) The distribution of $\mathrm{Cr}$ atoms across the $C_{0}$ iso-concentration surface (located at $x=0$ ), the $\alpha^{\prime}$ threshold is selected to $3 / 4$ maximum height of the maximum distribution. (b) The concentration of $\alpha^{\prime}$ obtained from the selected threshold is 58.72 at. pctCr.

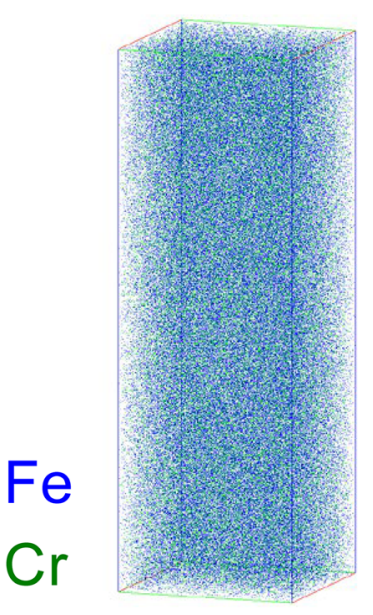

(a)

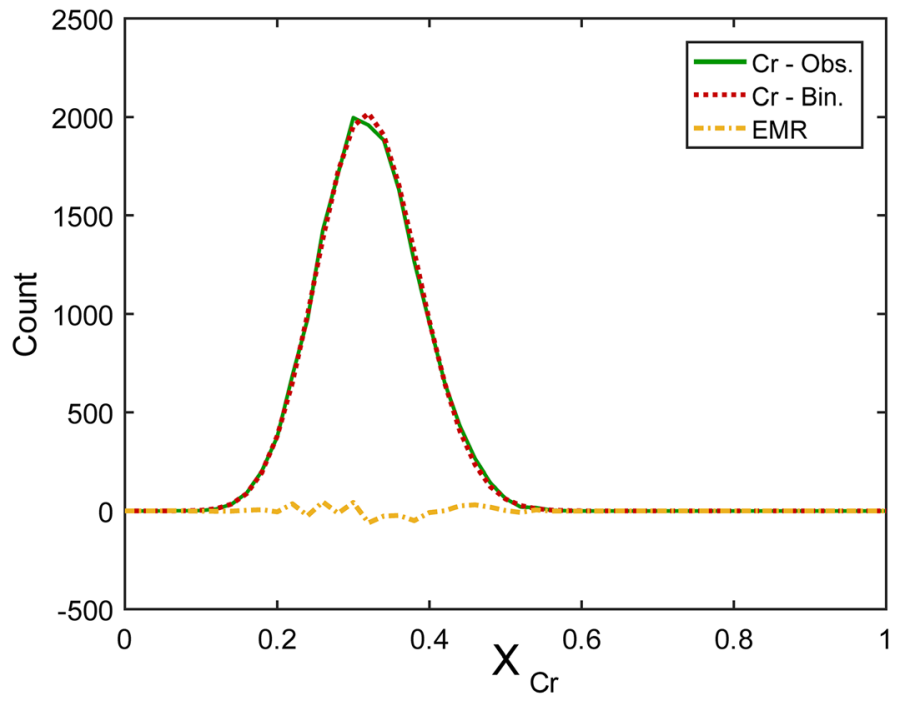

(b)

Fig. 3- (a) Atom map of $\mathrm{Fe}_{0.65} \mathrm{Cr}_{0.35}$ after solution treatment $20 \times 20 \times 60 \mathrm{~nm}^{3}$. (b) at. petCr distribution analysis of the (a) volume.

\section{B. Hardness Measurements}

It is well known that the $\mathrm{HV}$ of $\mathrm{Fe}-\mathrm{Cr}$-based alloys are greatly affected by the $\mathrm{Cr}$ fluctuations present in the ferrite phase. ${ }^{[18,41]}$ The general understanding is that the $\alpha^{\prime}$ formation in these alloys generates coherency strain that restricts dislocation mobility, causing significant loss of toughness. Thus, it is possible to detect phase separation and relate its kinetics to nucleation and growth or spinodal decomposition through the evolution of mechanical properties relative to the as-quenched reference state by $\Delta \mathrm{HV}$. 


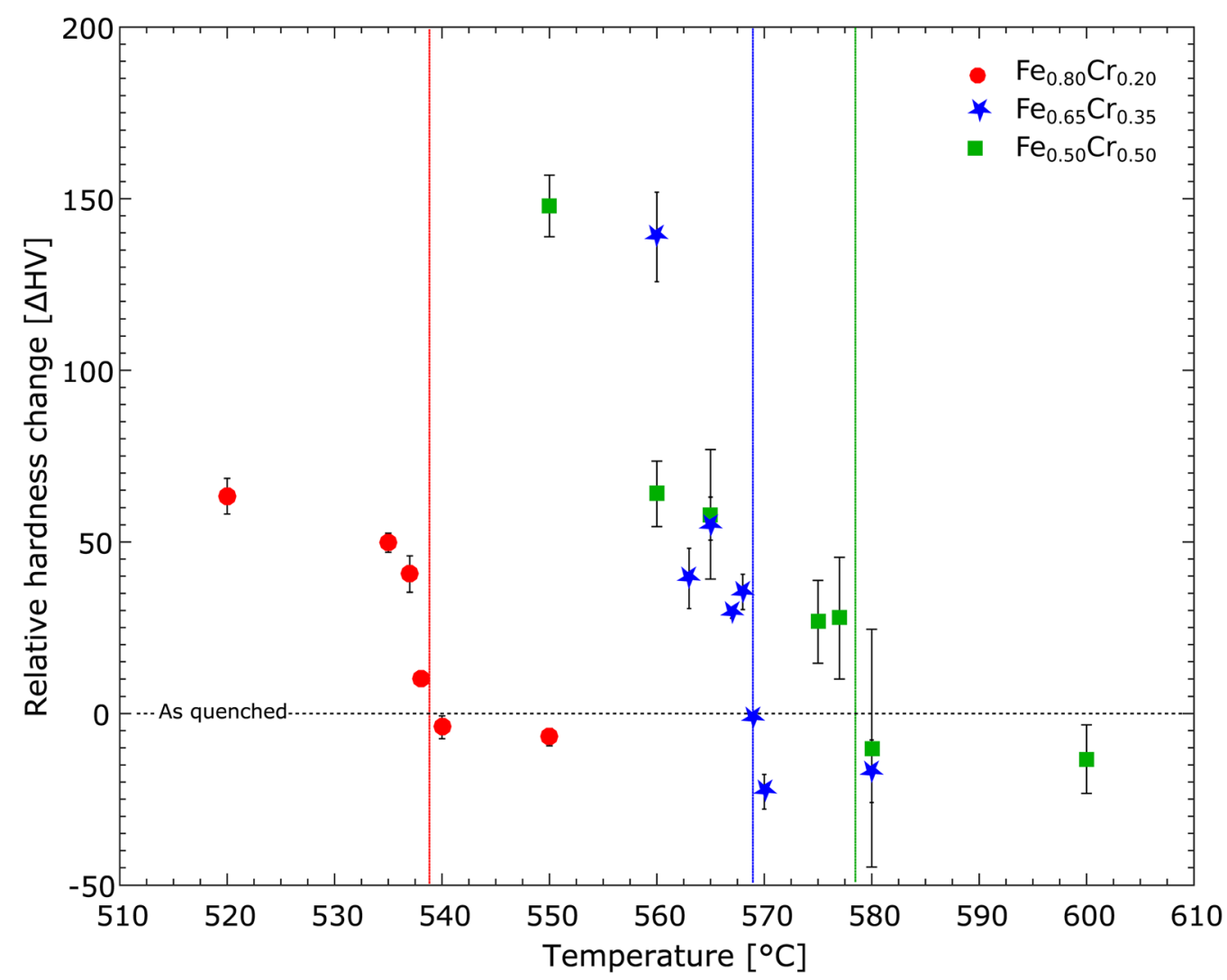

Fig. 4-Relative hardness $(\Delta \mathrm{HV})$ as described in Section II-B, error bars are the standard deviations. The vertical lines highlight the indicated limits of $\alpha^{\prime}$ formation, i.e., between the data points where $\Delta \mathrm{HV}>0$ and $\Delta \mathrm{HV} \leq 0$. Isothermal heat treatment after as-quenched solution treatment, with aging time $120 \mathrm{~h}$. In red, $\mathrm{Fe}_{0.80} \mathrm{Cr}_{0.20}$ decomposed by nucleation and growth, in blue $\mathrm{Fe}_{0.65} \mathrm{Cr}_{0.35}$ and in $\mathrm{green}^{\mathrm{Fe}} \mathrm{e}_{0.50} \mathrm{Cr}_{0.50}$, both decomposed by spinodal decomposition (Color figure online).

The $\Delta \mathrm{HV}$ of all investigated alloys is presented in Figure 4. If significant hardening develops during the first 120 hours, it indicates that phase separation is present during aging. On the other hand, if the $\Delta \mathrm{HV}$ values stay close to zero, it means that the alloys remain close to the as-quenched solution-treated state without significant at. pctCr amplitudes. Hence, the temperature window of the $\Delta \mathrm{HV}$ transition region is interesting to further study directly in 3D by APT to determine if phase separation is present.

The different phase separation characteristics of these alloys are largely attributed to the nature of their decomposition mechanism and its thermodynamic properties. Thus, note that the $\mathrm{Fe}_{0.80} \mathrm{Cr}_{0.20}$ alloy (indicated in Figure 4 by red circles) is expected to decompose through nucleation and growth at these temperatures, ${ }^{[42]}$ i.e., there is an $\alpha^{\prime}$ activation energy barrier that restricts the onset of phase separation. While $\mathrm{Fe}_{0.65} \mathrm{Cr}_{0.35}$ and $\mathrm{Fe}_{0.50} \mathrm{Cr}_{0.50}$ alloys (shown Figure 4 by stars and squares) are both known to be unstable, i.e., they decompose continuously without an activation energy barrier. Therefore, it is expected that the $\Delta \mathrm{HV}$ transition over the top of the miscibility gap at $\mathrm{Fe}_{0.50} \mathrm{Cr}_{0.50}$ is more gradual as the driving force is reduced, whereas, in relation to the nucleation process, in $\mathrm{Fe}_{0.80} \mathrm{Cr}_{0.20}, \Delta \mathrm{HV}$ exhibits more of a stepwise behavior. The result promotes a more careful APT investigation of the $\mathrm{Fe}_{0.80} \mathrm{Cr}_{0.20}$ alloy in the interval from $537{ }^{\circ} \mathrm{C}$ to 540
${ }^{\circ} \mathrm{C}$, investigation of the $\mathrm{Fe}_{0.65} \mathrm{Cr}_{0.35}$ alloy in the interval from $560{ }^{\circ} \mathrm{C}$ to $570{ }^{\circ} \mathrm{C}$, and an investigation of the $\mathrm{Fe}_{0.50} \mathrm{Cr}_{0.50}$ alloy in the interval from $565^{\circ} \mathrm{C}$ to $580{ }^{\circ} \mathrm{C}$.

\section{Atom Probe Tomography (APT)}

APT allows for 3D investigations of all elements with subnanometer resolution. In this work, mass-resolution was high enough to resolve all isotopes of $\mathrm{Fe}$ and $\mathrm{Cr}$ except the ${ }^{54} \mathrm{Cr}$ and ${ }^{54} \mathrm{Fe}$ isobars, which was not accounted for, the peak at $27 \mathrm{Da}$ was attributed to $\mathrm{Fe}^{2+}$. The background noise was in the range of 25 to 50 $\mathrm{ppm}$, which gives a very low detection limit as well. ${ }^{[43]}$ Thus, APT allows for highly accurate investigation of $\alpha^{\prime}$ and short-range $\mathrm{Cr}$ fluctuations in the vicinity of the limit of the miscibility gap.

\section{Analysis of the $\mathrm{Fe}_{0.80} \mathrm{Cr}_{0.20}$ alloy}

Based on the $\Delta \mathrm{HV}$ results, samples of the $\mathrm{Fe}_{0.80} \mathrm{Cr}_{0.20}$ alloy were prepared for APT after 120 hours of aging at $537^{\circ} \mathrm{C}$ and $540{ }^{\circ} \mathrm{C}$; the result is shown in Figure 5.

It is evident from Figure 5 that $\mathrm{Fe}_{0.80} \mathrm{Cr}_{0.20}$ contains dispersed precipitation of $\alpha^{\prime}$ phase present at $537{ }^{\circ} \mathrm{C}$, while at $540{ }^{\circ} \mathrm{C}$, there are no such precipitates. However, during the early stages of phase separation, $\alpha^{\prime}$ is not always this obvious. Thus, there is a need for statistical analysis to consistently quantify the strength of $\mathrm{Cr}-\mathrm{Cr}$ clustering and phase separation in-between samples. 


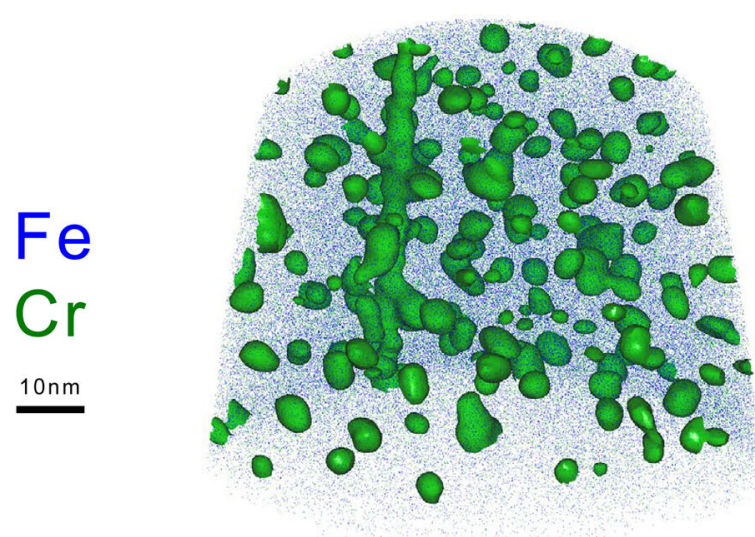

(a)

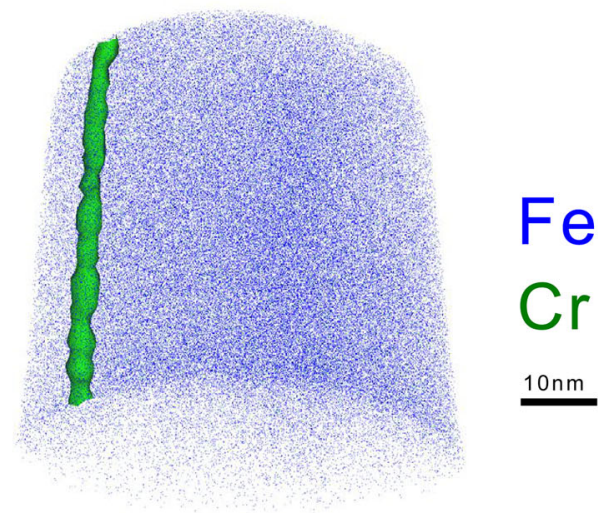

(b)

Fig. 5- $\mathrm{Fe}_{0.80} \mathrm{Cr}_{0.20}$ samples at $(a) 537{ }^{\circ} \mathrm{C}$ with $\alpha^{\prime}$ precipitates present and $(b)$ a homogeneous $\alpha$ phase at $540{ }^{\circ} \mathrm{C}$. (b) The iso-surface threshold selected according to Section II-B-E. At $540{ }^{\circ} \mathrm{C}$ a high at. petCr pillar is visible (also seen at $537{ }^{\circ} \mathrm{C}$ ), which is a characteristic feature of the low hit-density $\mathrm{Fe}\langle 110\rangle$ pole.

Hence, the statistical analysis of the $\mathrm{Fe}_{0.80} \mathrm{Cr}_{0.20}$ phase separation, compiled in Table III, serves as a good reference for further comparisons. In addition, in the case of the $\mathrm{Fe}_{0.80} \mathrm{Cr}_{0.20}$ alloy, the cluster extraction procedure proposed by Stephenson et al. ${ }^{[44]}$ was used to isolate $\alpha^{\prime}$ precipitates and obtain their composition through radial concentration profiles ${ }^{[45]}$ and the gyration radius has been used to obtain the Guinier radius $\left(r_{G}^{\alpha^{\prime}}\right)$ of $\alpha^{\prime} \cdot{ }^{[46]}$

Figure 5(b) displays a relatively homogenous sample without the presence of any $\alpha^{\prime}$ precipitates, but with a crystallographic low-density Fe-pole, which gives rise to the high-Cr region. It is an experimental artifact that would introduce a sample-biased error, which is not representative of the overall $\mathrm{Cr}$ segregation and therefore is excluded in the statistical analysis. Similarly, the less visible pole in Figure 5(a) is also excluded from the analysis presented in Table III. In Figure 5(a), the morphology consists of close to spherical Cr-enriched precipitates. At this point, the selection of at. pctCr threshold is crucial to highlight the morphology qualitatively given the high density of precipitates. Hence, the $\alpha^{\prime}$ threshold selection is made by proxigrams as described in Section II-B-E.

The morphology in Figure 5(a) clearly shows $\alpha^{\prime}$ precipitates which is a result of phase separation while in Figure 5(b), there are no precipitates which is why we believe we have located the limit of the miscibility gap even though the $\alpha^{\prime}$ precipitates do not reach the equilibrium composition. In experiments, equilibrium conditions are rarely met for numerous reasons, e.g., in $\mathrm{Fe}-\mathrm{Cr}$-reduced kinetics of transformation is expected as equilibrium is approached, ${ }^{[47]}$ in addition to the experimental uncertainties of precipitate composition measurements inherent by the field evaporation technique. However, these effects do not account for the lack of equilibrium; instead, this deviation is expected due to the precipitate size and the contribution of the surface energy in the early stages; this is previously well known as non-classical nucleation and growth. ${ }^{[48]}$

\section{Analysis of the $\mathrm{Fe}_{0.65} \mathrm{Cr}_{0.35}$ alloy}

During spinodal decomposition, as in the $\mathrm{Fe}_{0.65} \mathrm{Cr}_{0.35}$ alloy, the characterization of the $\alpha^{\prime}$ phase morphology is more sensitive to the selected iso-surfaces thresholds. The major difficulty is due to the interconnected structure that develops continuously. The result of spinodal decomposition is more of a gradual $\alpha^{\prime} \rightarrow \alpha$ morphological transition in comparison to nucleation and growth, that is when in this case the aging time is restricted to $120 \mathrm{hrs}$. Even though a wider transition range would suggest a greater undercooling from the MG limit to give greater $\mathrm{Cr}-\mathrm{Cr}$ interaction, it is seen by the $\triangle \mathrm{SRO}$ parameter that $\mathrm{Cr}-\mathrm{Cr}$ interaction in $\alpha^{\prime}$ in the $\mathrm{Fe}_{0.65} \mathrm{Cr}_{0.35}$ is weaker than in the $\mathrm{Fe}_{0.80} \mathrm{Cr}_{0.20}$ alloy at equivalent undercooling from the suggested miscibility gap during this transition. Yet, despite the lack of equilibrium, once again, it is still possible to follow the presence of phase separation through the $\alpha^{\prime} \mathrm{Cr}$ measurements.

In Figure 6, there is an evolution of the $\mathrm{Fe}_{0.65} \mathrm{Cr}_{0.35}$ morphology from $560{ }^{\circ} \mathrm{C}$ to $568{ }^{\circ} \mathrm{C}$ where there is a transition into a much more homogeneous state at 570 ${ }^{\circ} \mathrm{C}$. Still, at $570{ }^{\circ} \mathrm{C}$, the sample is far from as homogeneous as in the as-quenched state. It should be noted that a small region of nucleation and growth in-between $568{ }^{\circ} \mathrm{C}$ and $570{ }^{\circ} \mathrm{C}$ is not ruled out, since the driving force should be very low and could lead to heterogeneous precipitation outside of the probed volume. The statistical analysis of the $\mathrm{Fe}_{0.65} \mathrm{Cr}_{0.35}$ alloy is compiled in Table IV.

The $V$-based analysis reveals a rapid decrease of the $\mathrm{Cr}$ composition amplitudes caused by phase separation when approaching $570{ }^{\circ} \mathrm{C}$. The $\mathrm{Cr}$ composition measurement binning volume was 50 ions or approximately $1.6 \mathrm{~nm}^{3}$. There is at the same time as $V$ decreases one observes a rapid increase of the characteristic wavelength, obtained by autocorrelation in the analysis direction. In relation to the solution-treated state, the fluctuations at $570{ }^{\circ} \mathrm{C}$ may be attributed to its proximity to the miscibility gap even though the fluctuations are not large enough in amplitude to form $\alpha^{\prime}$. 


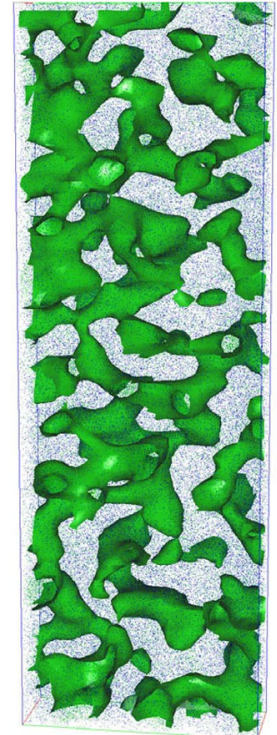

(a)

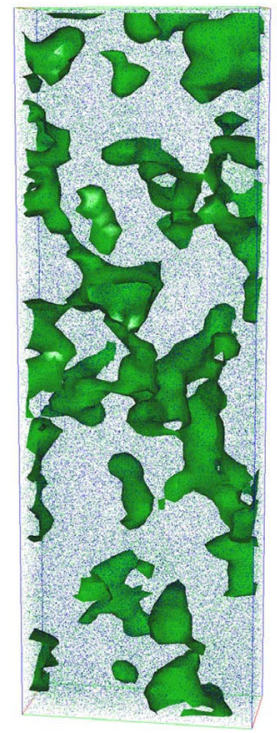

(b)

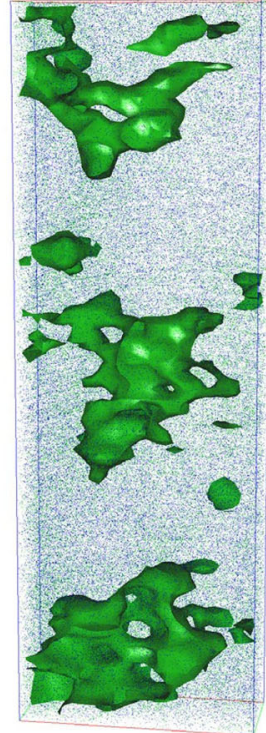

(c)

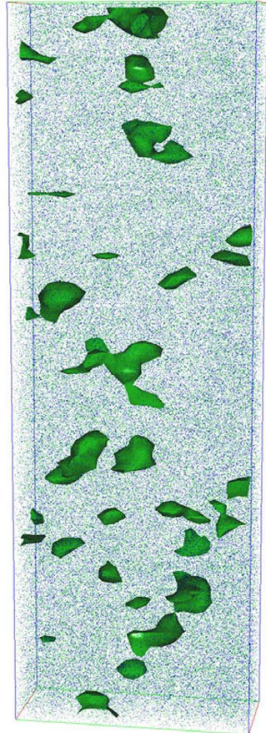

(d)

Fig. 6-Reconstructions of decomposed $\mathrm{Fe}_{0.65} \mathrm{Cr}_{0.35}$ alloys with iso-surfaces thresholds selected as in Section II-B-E for morphological comparison. (a) $560{ }^{\circ} \mathrm{C}$, (b) $563{ }^{\circ} \mathrm{C},(c) 568{ }^{\circ} \mathrm{C}$, and (d) $570{ }^{\circ} \mathrm{C}$ all aged for $120 \mathrm{~h}$, volume $10 \times 25 \times 75 \mathrm{~nm}^{3}$, Fe (blue) and $\mathrm{Cr}$ (green) $(\mathrm{Color}$ figure online).

The $\triangle \mathrm{SRO}$ and $\triangle \mathrm{NN}$ are local short-range quantification measurements that only consider $\mathrm{Cr}-\mathrm{Cr}$ interaction on a subnanometer scale. The $\Delta \mathrm{NN}$ includes a distance dependency, and thus, it makes it obvious that distribution analysis is dependent on binning volumes. Hence, comparing $V$ and $\Delta \mathrm{NN}$ between $\mathrm{Fe}_{0.65} \mathrm{Cr}_{0.35}$ and $\mathrm{Fe}_{0.80} \mathrm{Cr}_{0.20}$, we see similar trends and that there is approximately twice the amount of clustering in the alloy $\mathrm{Fe}_{0.65} \mathrm{Cr}_{0.35}$ vs. the $\mathrm{Fe}_{0.80} \mathrm{Cr}_{0.20}$ alloy for those samples that are considered as being outside of the miscibility gap (i.e., $570{ }^{\circ} \mathrm{C}$ vs. $540{ }^{\circ} \mathrm{C}$ ). In addition, the $\triangle \mathrm{SRO}$ is closely related to the strength of $\mathrm{Cr}-\mathrm{Cr}$ interactions, within a fixed spherical volume of maximum $0.25 \mathrm{~nm}$. Thus, considering $\Delta \mathrm{SRO}$, we see that the strength of $\mathrm{Cr}-\mathrm{Cr}$ interaction is equivalent outside of the miscibility gap but much stronger in the $\mathrm{Fe}_{0.80} \mathrm{Cr}_{0.20}$ alloy just inside the miscibility gap.

\section{Analysis of the $\mathrm{Fe}_{0.50} \mathrm{Cr}_{0.50}$ alloy}

In the $\mathrm{Fe}_{0.50} \mathrm{Cr}_{0.50}$ alloy, visualization of $\alpha^{\prime}$ is very sensitive to the threshold selection because of the high content of solute atoms and relatively low $\mathrm{Cr}$ amplitudes. The result is that small $\mathrm{Cr}$ fluctuations close to the miscibility gap limit can easily be missed or misinterpreted. Hence, a systematic sample-specific approach is necessary, as the one presented in Figure 2. The issue in the $\mathrm{Fe}_{0.50} \mathrm{Cr}_{0.50}$ alloy is that $\alpha^{\prime}$ is restricted by the limits of the miscibility gap, which approaches a single point at the consolute temperature. Meaning lower temperatures are required to allow for greater Cr fluctuation amplitudes. Thus, the consolute temperature of the miscibility gap is more difficult to determine than the limits of the lower $\mathrm{Cr}$ alloys. The evolution of $\alpha^{\prime}$ morphology of the $\mathrm{Fe}_{0.50} \mathrm{Cr}_{0.50}$ alloy can be seen in Figure 7 .

In Figures 7(c) and (d), there are still Cr-rich regions present whether these are just the top of the interconnected structure or just fluctuations present due to the proximity of the miscibility gap is not clear only from visual inspection. Therefore, kinetic measurements were made and analyzed by APT. Thus, comparing phase separation after 24 and 120 hours to quantify the evolution of $\mathrm{Cr}$ segregation at nanoscale near the indicated limit, the results are presented in Table V.

At $565{ }^{\circ} \mathrm{C}$ and $570{ }^{\circ} \mathrm{C}$, one can see a clearly interconnected structure of $\alpha^{\prime}$ (Figures 7(a) and (b)) and in Table $\mathrm{V}$, statistical analysis shows that there is phase separation present. However, the extent of phase separation is rapidly decreased when increasing the temperature from $565{ }^{\circ} \mathrm{C}$ to $570{ }^{\circ} \mathrm{C}$, which is an indication of a decreased driving force for phase separation. Thus, due to the above-mentioned reasons in this case, one needs to rely upon the statistical measurements and the expectation of a reduction in driving force to locate the limit of the miscibility gap. Furthermore, it is expected that there will still be significant clustering present just outside of the miscibility gap and in this case phase separation may be retarded by a sluggish sigma phase formation. ${ }^{[15]}$ From $570{ }^{\circ} \mathrm{C}$ to $578{ }^{\circ} \mathrm{C}$, the $V$ parameter has reduced to less than half and is becoming very close to the same value as for the $\mathrm{Fe}_{0.65} \mathrm{Cr}_{0.35}$ alloy at $570{ }^{\circ} \mathrm{C}$. Thus, given the $\Delta \mathrm{HV}$ indication (Figure 4), the kinetic evolution has been investigated by APT to see how the potential phase separation evolves with time at $578{ }^{\circ} \mathrm{C}$ and $580{ }^{\circ} \mathrm{C}$. In Table V, one can see that the $578{ }^{\circ} \mathrm{C}$ alloy has a structure that slowly but clearly evolves in $V$ with time (24 vs. 120 hours), this evolution is small but measurable considering the sensitivity of the method in the reference state and taken as an indication of phase separation. On the other hand, there is no evolution of the decomposition at $580{ }^{\circ} \mathrm{C}$ between 24 and 120 hours, indicating that $580{ }^{\circ} \mathrm{C}$ is outside of the miscibility gap. In addition, 
Table IV. Statistical APT Analysis of $\mathrm{Fe}_{0.65} \mathrm{Cr}_{0.35}$ After 120 h Aging Analyzed Volumes $25 \times 25 \times 75 \mathbf{n m}^{3}$

\begin{tabular}{lcccccccc}
\hline Alloy & Temp. $\left({ }^{\circ} \mathrm{C}\right)$ & Time $(\mathrm{h})$ & $V$ & $\Delta$ SRO & $V(1 \mathrm{st}-\mathrm{NN})$ & $V(5$ th-NN) & $\Delta$ NN (V) & Wavelength (nm) \\
\hline $\mathrm{Fe}_{0.65} \mathrm{Cr}_{0.35}$ & 560 & 120 & 0.961 & 0.412 & 0.308 & 0.670 & 0.362 & 11.0 \\
$\mathrm{Fe}_{0.65} \mathrm{Cr}_{0.35}$ & 563 & 120 & 0.457 & 0.139 & 0.094 & 0.258 & 0.164 & 13.2 \\
$\mathrm{Fe}_{0.65} \mathrm{Cr}_{0.35}$ & 568 & 120 & 0.417 & 0.122 & 0.092 & 0.244 & 0.152 & 20.4 \\
$\mathrm{Fe}_{0.65} \mathrm{Cr}_{0.35}$ & 570 & 120 & 0.163 & 0.041 & 0.046 & 0.108 & 0.062 & NA \\
$\mathrm{Fe}_{0.65} \mathrm{Cr}_{0.35}$ & 1100 & 2 & 0.029 & 0.002 & 0.021 & 0.024 & 0.003 & NA \\
\hline
\end{tabular}

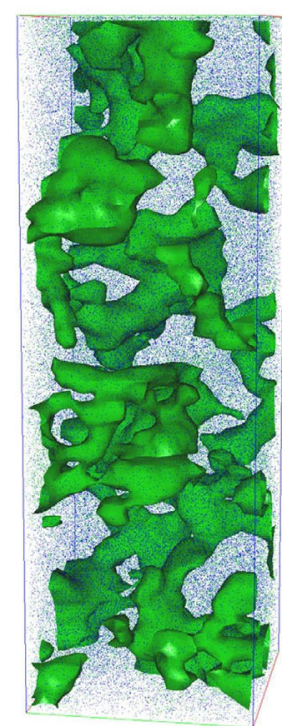

(a)

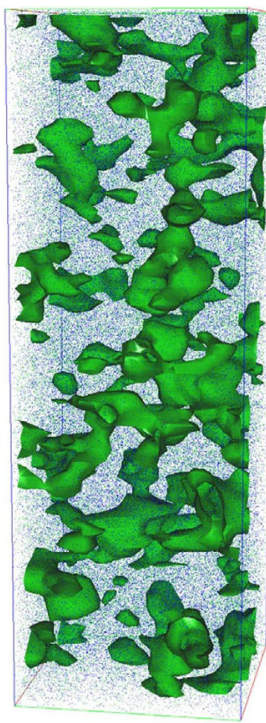

(b)

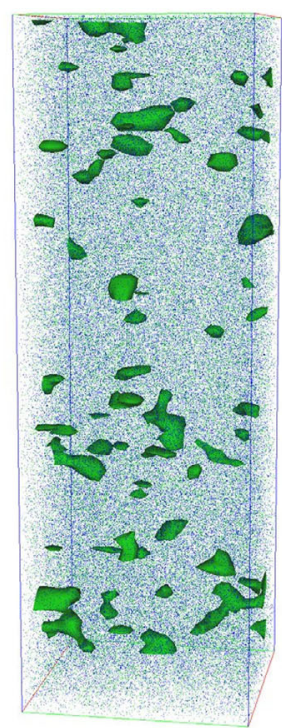

(c)

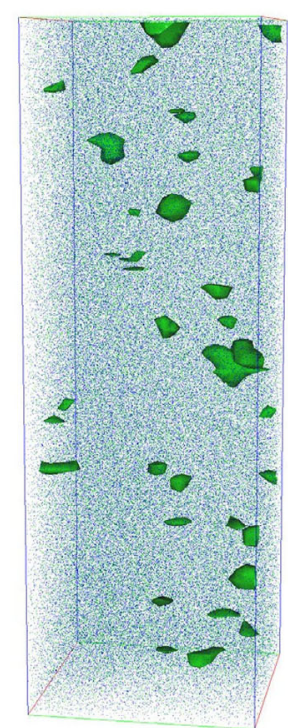

(d)

Fig. 7-APT results of the $\mathrm{Fe}_{0.50} \mathrm{Cr}_{0.50}$ alloys aged 120hrs, iso-surface threshold is set as described by Fig. 2. Displaying (a) an interconnected structure at $565{ }^{\circ} \mathrm{C},(b)$ semi-interconnected $\mathrm{Cr}$ fluctuations at $570{ }^{\circ} \mathrm{C},(c)$ a higher density of dispersed $\mathrm{Cr}$ fluctuations at $578{ }^{\circ} \mathrm{C}$ and $(d)$ dispersed $\mathrm{Cr}$ fluctuations at $580^{\circ} \mathrm{C}$. Volumes $25 \times 25 \times 75 \mathrm{~nm}^{3} \mathrm{Cr}$ (green) and $\mathrm{Fe}$ (blue) (Color figure online)

Table V. Statistical APT Analysis of $\mathrm{Fe}_{0.50} \mathrm{Cr}_{0.50}$ After 120 h Aging Analyzed Volumes $25 \times 25 \times 75 \mathbf{n m}^{3}$

\begin{tabular}{lcccccr}
\hline Alloy & Temp. $\left({ }^{\circ} \mathrm{C}\right)$ & Time & $V$ & $\Delta$ SRO & $V(1$ st $-\mathrm{NN})$ & $V(5$ th $-\mathrm{NN})$ \\
\hline $\mathrm{Fe}_{0.50} \mathrm{Cr}_{0.50}$ & 595 & 145 & 0.083 & 0.017 & 0.020 & $\Delta \mathrm{NN}$ \\
$\mathrm{Fe}_{0.50} \mathrm{Cr}_{0.50}$ & 580 & 120 & 0.189 & 0.041 & 0.044 & 0.044 \\
$\mathrm{Fe}_{0.50} \mathrm{Cr}_{0.50}$ & 580 & 24 & 0.187 & 0.035 & 0.039 & 0.105 \\
$\mathrm{Fe}_{0.50} \mathrm{Cr}_{0.50}$ & 578 & 120 & 0.228 & 0.045 & 0.042 & 0.085 \\
$\mathrm{Fe}_{0.50} \mathrm{Cr}_{0.50}$ & 578 & 24 & 0.186 & 0.033 & 0.034 & 0.119 \\
$\mathrm{Fe}_{0.50} \mathrm{Cr}_{0.50}$ & 570 & 120 & 0.444 & 0.094 & 0.084 & 0.093 \\
$\mathrm{Fe}_{0.50} \mathrm{Cr}_{0.50}$ & 565 & 120 & 0.847 & 0.182 & 0.184 & 0.046 \\
\hline
\end{tabular}

at short range after 120 hours, $\triangle \mathrm{SRO}$ and $\triangle \mathrm{NN}$ are greater in $\mathrm{Fe}_{0.50} \mathrm{Cr}_{0.50}$ at $578{ }^{\circ} \mathrm{C} 120$ hours than at 580 ${ }^{\circ} \mathrm{C} 120$ hours which is almost identical to $570{ }^{\circ} \mathrm{C} 120$ hours $\mathrm{Fe}_{0.65} \mathrm{Cr}_{0.35}$.

\section{Thermodynamic Description}

The limit of $\mathrm{Fe}-\mathrm{Cr}$ phase separation and its temporal evolution is determined by the thermodynamic descriptions of the system. The metastable miscibility gap has been re-optimized using the Thermo-Calc software with a second-order Redlich-Kister interaction parameter in the excess energy term. The new description is based on literature data, compiled in Table VI, and the experimental work presented in this paper, using the thermodynamic model in Section II-D. The thermodynamic $\mathrm{Fe}-\mathrm{Cr}$ description presented by Andersson and Sundman $^{[49]}$ has been used as it is currently implemented in the Thermo-Calc Software TCFE10 Steels/Fe-alloys database.

Experimentally, $\mathrm{Fe}-\mathrm{Cr}$ phase separation by $\alpha^{\prime}$ formation is generally explored at temperatures around 500 ${ }^{\circ} \mathrm{C}$, motivated by the rate of transformation. The solubility of $\mathrm{Cr}$ in $\alpha$ and $\alpha^{\prime}$ phases determines the limits 
Table VI. Experimental Data from Literature Focusing on Fe-Cr Phase Separation

\begin{tabular}{|c|c|c|c|}
\hline Reference & Material & Time & Technique \\
\hline \multirow[t]{3}{*}{ Inden and Dubeil ${ }^{[50]}$} & $\mathrm{Fe}_{0.85} \mathrm{Cr}_{0.15}$ & $10^{5}$ & MB \\
\hline & $\mathrm{Fe}_{0.30} \mathrm{Cr}_{0.70}$ & 35,500 & MB \\
\hline & $\mathrm{Fe}_{0.80} \mathrm{Cr}_{0.20}$ & 35,500 & MB \\
\hline Katano and Iizumi ${ }^{[51]}$ & $\mathrm{Fe}_{0.60} \mathrm{Cr}_{0.40}$ & 20 & SANS \\
\hline Novy et al. ${ }^{[42]}$ & $\mathrm{Fe}_{0.80} \mathrm{Cr}_{0.20}$ & 1067 & APT \\
\hline Chandra $^{[52]}$ & $\mathrm{Fe}_{0.66} \mathrm{Cr}_{0.24}$ & 1738 & MB \\
\hline Bergner $^{[53]}$ & $\mathrm{Fe}_{0.91} \mathrm{Cr}_{0.09}$ & $\mathrm{Na}^{*}$ & SANS \\
\hline \multirow[t]{2}{*}{ Gou et al..$^{[54]}$} & $\mathrm{Fe}_{0.75} \mathrm{Cr}_{0.24} \mathrm{Ni}_{0.01}$ & 10,000 & APT \\
\hline & $\mathrm{Fe}_{0.70} \mathrm{Cr}_{0.26} \mathrm{Ni}_{0.04}$ & 10,000 & APT \\
\hline Miller et al. ${ }^{[55]}$ & $\mathrm{Fe}_{\mathrm{Bal} .} \mathrm{Cr}_{0.17,0.19,0.32,0.45}$ & 500 & FIM-APT \\
\hline Kuwano ${ }^{[56]}$ & $\mathrm{Fe}_{1-\mathrm{X}} \mathrm{Cr}_{\mathrm{X}}$ & 50 & MB \\
\hline Williams and Paxton ${ }^{[57]}$ & $\mathrm{Fe}_{1-\mathrm{X}} \mathrm{Cr}_{\mathrm{X}}$ & 1000 & HV / RES \\
\hline This Work & $\mathrm{Fe}_{\mathrm{Bal} .} \mathrm{Cr}_{0.20,0.35,0.50}$ & 120 & APT \\
\hline
\end{tabular}

$M B$ Mössbauer spectroscopy, $S A N S$ small-angle neutron scattering, $A P T$ atom probe tomography, $H V$ Vickers hardness, $R E S$ resistivity measurements.

*Irradiated samples 0.6 and $1.5 \mathrm{dPa}$.

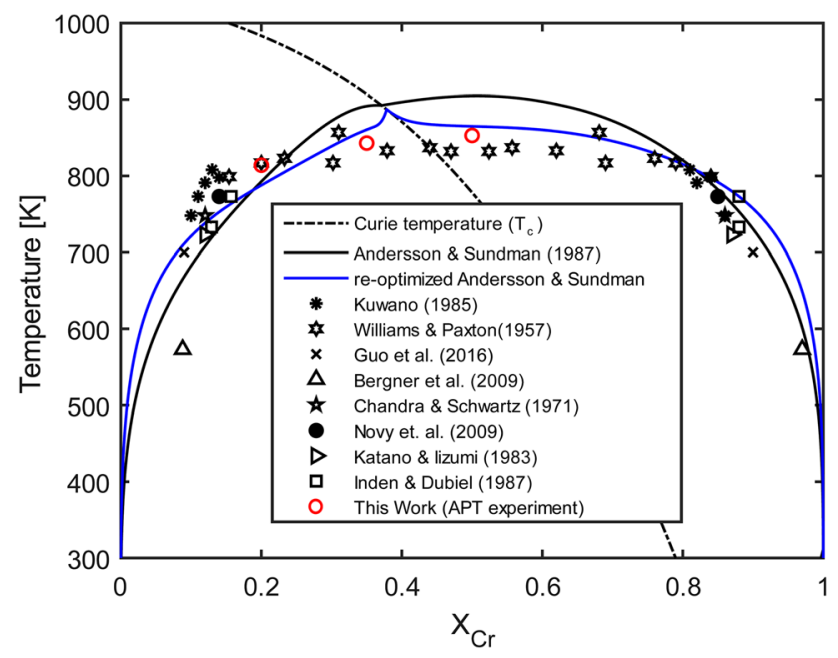

Fig. 8-CALPHAD re-optimization of the Fe-Cr miscibility gap, using the Thermo-Calc software. ${ }^{[39]}$

of the miscibility gap and thus are used as input for the new re-optimization. Therefore, long-term heat treatments are sought out, and the near-equilibrium $\mathrm{Cr}$ content in $\alpha^{\prime}$ is used as miscibility gap estimates. ${ }^{[42,50-53]}$ The upper limit of the miscibility gap has been investigated on several occasions, e.g., see Reference 55, 57, 15 , but not with the same accuracy as in this work. Still, some of the prior work (e.g., Williams, ${ }^{[57]}$ ) also suggest that the miscibility gap should be lower than the current thermodynamic descriptions. ${ }^{[14,49,58]} \mathrm{A}$ reason for these non-conclusive results in literature could be the use of indirect experimental techniques that lacks to distinguish between phase separation and $\mathrm{Cr}-\mathrm{Cr}$ clustering. Thus, the results obtained in this work by APT in combination with the literature data are presented in Table VI are compiled in Figure 8, presented with the corresponding re-optimization.

The re-optimization of the miscibility gap results in an addition of +500 to the regular term ${ }^{\circ} L$, and a subregular term, ${ }^{2} L=+2500$, to partially account for clustering using the excess energy term. The addition of these parameters improves the description of the consolute temperature of the miscibility gap and reveals a "Nishizawa horn" that appears due to the magnetic transition. Still, this re-optimized miscibility gap is by no means final but only shows what can be done using the excess term. In addition, the $\mathrm{Cr}$ solubility in $\alpha$ on the $\mathrm{Fe}$ side is well established but it could not accurately be accounted for when trying to include SRO. Thus, in a revised thermodynamic description, one should include the new magnetic description as by Xiong et al. ${ }^{[59]}$ and the 3rd-generation unary descriptions of $\mathrm{Fe}$ and $\mathrm{Cr}$. Still, an accurate consolute temperature of the miscibility gap is important to determine the undercooling which drives the temporal evolution of phase separation.

\section{CONCLUSIONS}

- The limit of $\alpha^{\prime}$ formation is in this work defining the limit of the metastable miscibility gap, and $\mathrm{Cr}-\mathrm{Cr}$ clustering is separated from phase separation. This definition is supported by the fact that $\mathrm{Cr}-\mathrm{Cr}$ clustering outside the miscibility gap is not large enough to generate a significant HV impact. The $\mathrm{Cr}-\mathrm{Cr}$ clustering should be regarded as a different temperature-dependent phenomenon in need of further investigation.

- The APT result in this work is in good agreement with a selection of the most cited experimental studies of Fe-Cr alloys (seen in Figure 8). However, the consolute temperature of the miscibility gap of $580{ }^{\circ} \mathrm{C} \pm 1{ }^{\circ} \mathrm{C}$ at $\mathrm{Fe}_{0.50} \mathrm{Cr}_{0.50}$ is set slightly higher than obtained by, e.g., Williams. ${ }^{[57]}$ This deviation is probably due to high-precision thermal treatment and state-of-the-art APT characterization used in this work. 
- One of the findings in this work is that the phase separation through APT Cr composition distribution analysis confirms that the limit of miscibility gap at $\mathrm{Fe}_{0.50} \mathrm{Cr}_{0.50}$ is higher than at $\mathrm{Fe}_{0.65} \mathrm{Cr}_{0.35}$, i.e., the miscibility gap is not flat at the top. A reason as to why the critical temperature of the $\mathrm{Fe}_{0.50} \mathrm{Cr}_{0.50}$ alloy might be interpreted as located below the $\mathrm{Fe}_{0.65} \mathrm{Cr}_{0.35}$ alloy by $\Delta \mathrm{HV}$ is because there is a significant drop of $\Delta \mathrm{HV}$ around/just before $570{ }^{\circ} \mathrm{C}$ in the $\mathrm{Fe}_{0.50} \mathrm{Cr}_{0.50}$ alloy, seen in Figure 4. However, in the $\mathrm{Fe}_{0.50} \mathrm{Cr}_{0.50}$ alloy, there is a long gradual transition over the top of the MG from the first significant $\Delta \mathrm{HV}$ drop which occurs before the first noticeable $\Delta \mathrm{HV}$ drop in the $\mathrm{Fe}_{0.65} \mathrm{Cr}_{0.35}$ alloy, hence a probable source of confusion in indirect measurements.

- Apart from the $\triangle \mathrm{SRO}$ analysis, the RDF has been used to investigate the presence of a 2 nd maximum on its curve to determine the presence of segregation periodicity in the alloys where $\alpha^{\prime}$ could not clearly be determined. Thus, it exists a 2 nd maximum in the $\mathrm{Fe}_{0.50} \mathrm{Cr}_{0.50} \mathrm{RDF}$ at $565^{\circ} \mathrm{C}, 570{ }^{\circ} \mathrm{C}$, and $578^{\circ} \mathrm{C}$ after 120 hours while it is absent at $580{ }^{\circ} \mathrm{C}$. The disappearance of the 2nd RDF peak correlates well with the disappearance of $\Delta \mathrm{HV}$ increases as well. This supports the conclusion that $580{ }^{\circ} \mathrm{C}$ is the upper limit for $\alpha^{\prime}$ at $\mathrm{Fe}_{0.50} \mathrm{Cr}_{0.50}$ apart from $\Delta \mathrm{SRO}$ and $\Delta \mathrm{NN}$. Using the RDFs, it is possible to see that there are no $2^{\text {nd }}$ maxima at $570{ }^{\circ} \mathrm{C} \mathrm{Fe}_{0.65} \mathrm{Cr}_{0.35}$ nor at 540 ${ }^{\circ} \mathrm{C} \mathrm{Fe}_{0.80} \mathrm{Cr}_{0.20}$, which means there is no repeating periodicity present. Therefore, these temperatures are identified as the upper limit of $\alpha^{\prime}$ formation and thus the limit of the miscibility gap. These RDF curves are included in Appendix A.

\section{ACKNOWLEDGMENTS}

The financial support from Centre National de la Recherche Scientifique (CNRS), Region-Normandie, and Carl Tryggers Research Foundation is gratefully acknowledged. This work was partly carried out owing to the experimental GENISIS platform. GENISIS is supported by the region Haute Normandie, the Metropole Rouen Normandie, the CNRS via LABEX EMC, and the French National Research Agency as part of the program "Investissement d'avenir" ARN-11-EQPX-0020. This work was also partly performed within the Competence Center Hero-m 2i financed by VINNOVA, the Swedish Governmental Agency for Innovation Systems, Swedish Industry, and KTH Royal Institute of Technology. One of the authors (MS) would like to thank Prof. Wei Xiong for useful discussions.

\section{FUNDING}

Open access funding provided by Royal Institute of Technology..

\section{OPEN ACCESS}

This article is licensed under a Creative Commons Attribution 4.0 International License, which permits use, sharing, adaptation, distribution and reproduction in any medium or format, as long as you give appropriate credit to the original author(s) and the source, provide a link to the Creative Commons licence, and indicate if changes were made. The images or other third party material in this article are included in the article's Creative Commons licence, unless indicated otherwise in a credit line to the material. If material is not included in the article's Creative Commons licence and your intended use is not permitted by statutory regulation or exceeds the permitted use, you will need to obtain permission directly from the copyright holder. To view a copy of this licence, visit http://creat ivecommons.org/licenses/by/4.0/.

\section{APPENDIX A: THE NORMALIZED RDF'S FROM $25 \times 25 \times 25$ NM VOLUMES}

The slope of the $\mathrm{A} 1 \mathrm{Fe}_{0.80} \mathrm{Cr}_{0.20} 120$ hours at $540{ }^{\circ} \mathrm{C}$ sample is due to minor crystallographic poles that strongly affect $\mathrm{Cr}$ segregation but not large enough to be visible in the reconstruction. A2 shows Cr-enriched region with a radius smaller than $4 \mathrm{~nm}$. In A3 $\mathrm{Fe}_{0.50} \mathrm{Cr}_{0.50} 120$ hours at $578{ }^{\circ} \mathrm{C}$, there is an increase in $\mathrm{Cr}$ again from $8 \mathrm{~nm}$ which indicates a periodic structure. A4 shows no periodic $\mathrm{Cr}$ enrichment at this length scale.

\section{REFERENCES}

1. H.D. Newell: Met. Prog., 1949, vol. 49, pp. 977-1006.

2. K.H. Lo, C.H. Shek, and J.K.L. Lai: Mater. Sci. Eng., 2009, vol. 65 , pp. 39-104.

3. C. Capdevila, J. Chao, J.A. Jimenez, and M.K. Miller: Mater. Sci. Technol., 2013, vol. 29, pp. 1179-84.

4. D. Terentyev, L. Malerba, and A.V. Barashev: Philos. Mag. Lett., 2005, vol. 85, pp. 587-94.

5. J. Wallenius, P. Olsson, L. Malerba, and D. Terentyev: Nucl. Instrum. Methods Phys. Res. Sect. B, 2007, vol. 255, pp. 68-74.

6. M.A. Choudhary, J. Kundin, and H. Emmerich: Philos. Mag. Lett., 2012, vol. 92, pp. 451-58.

7. K.L. Wong, H.-J. Lee, J.-H. Shim, B. Sadigh, and B.D. Wirth: $J$. Nucl. Mater., 2009, vols. 386-388, pp. 227-30.

8. T. Manninen: Mechanical Properties of Ferritic Stainless Steels at Elevated Temperature, https://www.academia.edu/9039435/Mech anical_Properties_of_Ferritic_Stainless_Steels_at_Elevated_Temp erature. Accessed 1 December 2015.

9. T. Zhang, Y. Han, W. Wang, Y. Gao, Y. Song, and X. Ran: Acta Metall. Sin., 2020, vol. 33, pp. 1289-1301.

10. M. Hillert: Acta Metall., 1961, vol. 9, pp. 525-35.

11. J.W. Gibbs: The Scientific Papers of J. Willard Gibbs, Ph.D., LL.D., vol. 1 Thermodynamics, Longmans, Green, and CO., 39 Paternoster Row, London, 1906.

12. J.W. Cahn: Acta Metall., 1961, vol. 9, pp. 795-801.

13. W. Xiong, M. Selleby, Q. Chen, J. Odqvist, and Y. Du: Crit. Rev. Solid State Mater. Sci., 2010, vol. 35, pp. 125-52.

14. W. Xiong, P. Hedström, M. Selleby, J. Odqvist, M. Thuvander, and Q. Chen: Calphad, 2011, vol. 35, pp. 355-66.

15. H. Kuwano: Trans. Jpn. Inst. Met., 1985, vol. 26, pp. 473-81.

16. Y. Li, Y. Pang, X. Wu, and W. Liu: Modelling Simul. Mater. Sci. Eng., 2014, vol. 22, p. 035009.

17. A. Dahlström, F. Danoix, P. Hedström, J. Odqvist, and H. Zapolsky: Scripta Mater., 2020, vol. 180, pp. 62-65. 
18. F. Danoix and P. Auger: Mater. Charact., 2000, vol. 44, pp. 177-201.

19. M.K. Miller and R.G. Forbes: Atom-Probe Tomography, Springer, Boston, 2014.

20. B. Gault, F. Danoix, K. Hoummada, D. Mangelinck, and H. Leitner: Ultramicroscopy, 2012, vol. 113, pp. 182-91.

21. M.P. Moody, B. Gault, L.T. Stephenson, D. Haley, and S.P. Ringer: Ultramicroscopy, 2009, vol. 109, pp. 815-24.

22. F. Vurpillot, M. Gruber, G. Da Costa, I. Martin, L. Renaud, and A. Bostel: Ultramicroscopy, 2011, vol. 111, pp. 1286-94.

23. M. Wada: Surf. Sci., 1984, vol. 145, pp. 451-65.

24. D. Blavette, G. Grancher, and A. Bostel: J. Physique Colloques, 1988, vol. 49, pp. C6-433-C6-438.

25. E.A. Marquis: Dissertation, Northwestern University, 2002.

26. B. Gault, M.P. Moody, J.M. Cairney, and S.P. Ringer: Atom Probe Microscopy, Springer, New York, 2012.

27. N. Pettersson, S. Wessman, M. Thuvander, P. Hedström, J. Odqvist, R.F.A. Pettersson, and S. Hertzman: Mater. Sci. Eng. $A$, 2015, vol. 647 , pp. $241-48$

28. S.M. Dubiel and J. Żukrowski: Acta Mater., 2013, vol. 61, pp. $6207-12$.

29. A.V. Ceguerra, M.P. Moody, L.T. Stephenson, R.K.W. Marceau, and S.P. Ringer: Philos. Mag., 2010, vol. 90, pp. 1657-83.

30. M.P. Moody, B. Gault, L.T. Stephenson, R.K.W. Marceau, R.C. Powles, A.V. Ceguerra, A.J. Breen, and S.P. Ringer: Microsc. Microanal., 2011, vol. 17, pp. 226-39.

31. J. Zhou, J. Odqvist, M. Thuvander, and P. Hedström: Microsc. Microanal., 2013, vol. 19, pp. 665-75.

32. A.V. Ceguerra, R.C. Powles, M.P. Moody, and S.P. Ringer: Phys. Rev. B., 2010, https://doi.org/10.1103/physrevb.82.132201.

33. S. Mukherjee, N. Kodali, D. Isheim, S. Wirths, J.M. Hartmann, D. Buca, D.N. Seidman, and O. Moutanabbir: Phys. Rev. B, 2017, vol. 95 , p. 161402.

34. M.Yu. Lavrentiev, D. Nguyen-Manh, and S.L. Dudarev: J. Nucl. Mater., 2018, vol. 499, pp. 613-21.

35. M.Yu. Lavrentiev, R. Drautz, D. Nguyen-Manh, T.P.C. Klaver, and S.L. Dudarev: Phys. Rev. B, 2007, vol. 75, p. 014208.

36. F. Danoix, G. Grancher, A. Bostel, and D. Blavette: Ultramicroscopy, 2007, vol. 107, pp. 739-43.

37. D.J. Larson, T.J. Prosa, R.M. Ulfig, B.P. Geiser, and T.F. Kelly: Local Electrode Atom Probe Tomography: A User's Guide, Springer, New York, 2013.

38. H.L. Lukas, S.G. Fries, and B. Sundman: Computational Thermodynamics - The Calphad Method, Cambridge University Press, Cambridge, 2007.
39. J.-O. Andersson, T. Helander, L. Höglund, P. Shi, and B. Sundman: Calphad, 2002, vol. 26, pp. 273-312.

40. F. Danoix, J. Lacaze, A. Gibert, D. Mangelinck, K. Hoummada, and E. Andrieu: Ultramicroscopy, 2013, vol. 132, pp. 193-98.

41. C. Pareige, S. Novy, S. Saillet, and P. Pareige: J. Nucl. Mater., 2011, vol. 411, pp. 90-96.

42. S. Novy, P. Pareige, and C. Pareige: J. Nucl. Mater., 2009, vol. 384, pp. 96-102.

43. W. Lefebvre-Ulrikson, F. Vurpillot, and X. Sauvage, eds.: in Atom Probe Tomography Put Theory Into Practice. Academic Press, New York, 2016, p. iii.

44. L.T. Stephenson, M.P. Moody, P.V. Liddicoat, and S.P. Ringer: Microsc. Microanal., 2007, vol. 13, pp. 448-63.

45. A. Deschamps, C. Sigli, T. Mourey, F. de Geuser, W. Lefebvre, and B. Davo: Acta Mater., 2012, vol. 60, pp. 1917-28.

46. M.K. Miller: Atom Probe Tomography: Analysis at the Atomic Level, Springer, US, 2000.

47. T. Barkar, L. Höglund, J. Odqvist, and J. Ågren: Comput. Mater. Sci., 2018, vol. 143, pp. 446-53.

48. T. Philippe and D. Blavette: Philos. Mag., 2011, vol. 2011, pp. 4606-22.

49. J.-O. Andersson and B. Sundman: Calphad, 1987, vol. 11, pp. 83-92.

50. S.M. Dubiel and G. Inden: Z. Metallkd., vol. 1987, p. 544.

51. S. Katano and M. Iizumi: Physica $B+C$, 1983, vol. 120, pp. 392-96.

52. D. Chandra and L.H. Schwartz: Metall. Trans, 1971, vol. 2, pp. 511-19.

53. F. Bergner, A. Ulbricht, and C. Heintze: Scripta Mater., 2009, vol. 61 , pp. 1060-63.

54. W. Guo, D.A. Garfinkel, J.D. Tucker, D. Haley, G.A. Young, and J.D. Poplawsky: Nanotechnology, 2016, vol. 27, p. 254004.

55. M.K. Miller, J.M. Hyde, M.G. Hetherington, A. Cerezo, G.D.W. Smith, and C.M. Elliott: Acta Metall. Mater., 1995, vol. 43, pp. 3385-3401.

56. H. Kuwano: Trans. Jpn. Inst. Met., 1985, vol. 26, pp. 482-91.

57. R.O. Williams and H.W. Paxton: J. Iron Steel Inst., 1957, vol. 185, p. 358.

58. Y. Ustinovshikov and B. Pushkarev: J. Alloys Compds., 2005, vol. 389, pp. 95-101.

59. W. Xiong, Q. Chen, P.A. Korzhavyi, and M. Selleby: Calphad, 2012, vol. 39, pp. 11-20.

Publisher's Note Springer Nature remains neutral with regard to jurisdictional claims in published maps and institutional affiliations. 